\title{
PLEOMORPHIC LIPOSARCOMA PRESENTING AS EXTRA- CARDIAC MEDIASTINAL MASS LEADING TO CARDIAC COMPRESSION
}

\author{
Aliena Badshah1, Zoia Ehsan Khattak¹, Israr Khan², Arooba Naeem¹, Mohammad Humayun'1 \\ ${ }^{1}$ Department of Medicine, Khyber Teaching Hospital, Peshawar - Pakistan
}

\begin{abstract}
A 45-year-old male presented with a 3-months history of fever associated with dyspnea, orthopnea, weight loss, chest pain, and anorexia. Past history was notable for cigarette smoking of 5 packs per year. Examination findings suggested clubbing, raised jugular venous pulse and pedal edema. Characteristic findings on systemic examination were displaced apex beat, sternal heave, bibasilar crepitations, distended abdomen, and the presence of shifting dullness. Echocardiography revealed an extracardiac mass collapsing mostly the right side of the heart. Later, multidetector computed tomography scan (MDCT) was done which detected a mediastinal mass crossing midline, significantly compressing right sided cardiac chambers, adjacent segments of major arteries and veins, and displaced esophagus to the left. An ultrasound guided biopsy confirmed the diagnosis of pleomorphic liposarcoma. The objective of reporting this case of pleomorphic liposarcoma is to keep our differentials broad when we get cases with typical cardiac symptoms. Sometimes the etiology could be extracardiac.
\end{abstract}

Key words: Pleomorphic liposarcoma; Mediastinal mass; Extracardiac mass.

This article may be cited as: Badshah A, Khattak ZE, Khan I, Naeem A, Humayun M. Pleomorphic liposarcoma presenting as extra-cardiac mediastinal mass leading to cardiac compression. J Med Sci 2021 January;29(1):52-55

\section{INTRODUCTION}

Liposarcomas are the malignant tumors of mesenchymal origin, more common in extremities and retroperitoneum, and rarely arise in mediastinum. People aged 20-70 years are most commonly affected with a peak incidence in the fifth decade of life. They are classified based on histological appearance into well differentiated, dedifferentiated, myxoid (common in children), and pleomorphic. Pleomorphic sarcoma is characterized by a varying number of pleomorphic lipoblasts merged in the background of undifferentiated sarcomatous areas ${ }^{1,2}$. It has a prevalence of $5-10 \%$ of all of the liposarcomas ${ }^{3}$. and $1-2 \%$ of all mediastinal tumors. They are the most malignant and are initially ignored but signs and symptoms of compression or invasion usually follow later as their size increases. Symptoms vary depending upon the location of tumor ${ }^{4}$. Herein, we describe a mediastinal tumor that mimics the signs of right sided heart failure e.g., edema, raised jugular venous pressure (JVP), breathlessness, distended veins, ascites, and pleural effusion. The tumor is difficult to diagnose on imaging and histopathology due to low adipose

\section{Correspondence}

Dr. Aliena Badshah

Department of Medicine, Khyber Teaching Hospital,

Peshawar - Pakistan

Email: alienabadshah@yahoo.com

Cell: +92-335-5950615

Date received: $02-01-2021$

Date revised: 11-03-2021

Date accepted: 16-03-2021 tissue content. The key to accurate diagnosis is taking adequate tissue samples from adipose and non-adipose tissues. Our patient presented with symptoms attributable to cardiovascular involvement and nonspecific constitutional signs and symptoms, and an extensive workup was done to reach the final diagnosis.

\section{CASE REPORT}

A 45-year-old normoglycemic and normotensive male presented to the medical outpatients with a 3-months history of fever associated with rigors and chills. He also complained of shortness of breath on daily activities. He had lost about $8 \mathrm{~kg}$ weight and his weight was down from $74 \mathrm{~kg}$ to $66 \mathrm{~kg}$ during this period. There was also left sided chest pain and anorexia. Personal history was positive for cigarette smoking of 5 packs per year in the past and disturbed sleep due to orthopnea. He denied any changes in bowel and bladder habits. The past medical history, past surgical history and family history were not significant. On physical examination, he looked quite debilitated. He had a blood pressure of $90 / 60 \mathrm{~mm} \mathrm{Hg}$, pulse 90 beats/minute, temperature $98 \mathrm{~F}$, and oxygen saturation of $96 \%$. Positive findings on examination included anemia, clubbing involving both fingers and toes, raised JVP, distended neck veins (see Figure 1), positive hepatojugular reflux, and pedal edema. No cyanosis and lymphadenopathy were appreciated. On chest inspection, there were intercostal 
Pleomorphic Liposarcoma Presenting As Extra-Cardiac Mediastinal Mass Leading To Cardiac Compression.

recessions, and the apex beat was visibly displaced and located along the anterior axillary line in the $6^{\text {th }}$ intercostals space. The sternal heave was positive on palpation. A plueropericardial rub was audible on auscultation. Respiratory examination revealed a central trachea and bibasilar fine crepitations although heart sounds could be heard in lower chest zones when auscultated from the back. The abdominal examination demonstrated a distended abdomen, and positive shifting dullness. There was no hepatosplenomegaly. Central Nervous System examination was generally normal. Baseline investigations were sent to laboratory and we had the following results (see Table 1)

Abdominal and Pelvic ultrasound showed mild to moderate ascites and mild left sided pleural effusion. Kidneys on both sides were mildly echogenic. There was a predominantly echogenic lesion seen in epigastrium measuring $11 \times 12 \mathrm{~cm}$ with no vascularity. On echocardiography, left atrium, left ventricle and right atrium were normal in size but right side was collapsed by an extra-cardiac mass especially at the right atrium and tricuspid valve level. Tricuspid valve was compressed giving a $12 \mathrm{mmHg}$ pressure gradient while other valves were normal. Extracardiac mass was collapsing mostly the right side of the heart. Inferior vena cava (IVC) was enlarged without respiratory variation, and there was sluggish flow across it. Moderate mitral regurgitation (MR), mild tricuspid regurgitation (TR) and pulmonary hypertension were noted. Left ventricular systolic functions were good and there was a trace aortic regurgitation (AR).

On multidetector computed tomography (MDCT), there was a large, mainly anterior and mid mediastinal right sided heterogenous attenuation mass crossing midline, extending to the left involving pericardium and significantly compressing right cardiac chambers, adjacent segments of superior vena cava, IVC, descending thoracic aorta, left atrium, right sided pulmonary veins, and also compressed and displaced esophagus to the left (see Fig 2). There was minimal pleural effusion, and left lower lung ground had glass haze. A small sub centimeter hypodense focus in the left hepatic lobe was found, which was indeterminate on a single phase study. Prominent mildly enlarged mediastinal nodes at sub-carinal aortopulmonary window and perivascular compartment were also noticed. Moreover, limited abdominal sections showed ascites and edematous liver.

Finally, an ultrasound guided biopsy of the mass was carried out that showed cores of fibro adipose muscular tissue showing a high grade sarcoma interspersed with multinucleated lipoblasts, and 10-20 mitoses were seen in a single focus. A diagnosis of pleomorphic sarcoma was made based on the report. Table 2 enlists the common pathological lesions found in different locations in the mediastinum. A cardiovascular surgeon was involved keeping in mind the clinical picture and after interpreting the imaging scan and biopsy findings. The tumor could not be excised due to the extensive nature of the procedure involved; therefore, the patient was referred to oncology unit for chemotherapy.

\section{DISCUSSION}

Liposarcomas are the malignant adipocytic tumours of mesenchymal origin and mediastinum is an uncommon site of such tumours. In the mediastinum, it is thought to arise from adult thymus or from mesenchymal cells capable of lipogenesis. WHO in 2002 classified liposarcomas based on histological types such as well differentiated, dedifferentiated, myxoid (common in children), pleomorphic, and mixed type. five to ten percent of all of the liposarcomas and 1-2 \% of all mediastinal tumors are pleomorphic liposarcomas. They are the most malignant and contain variable number of pleomorphic lipoblasts. Areas of lipogenesis differ in different tumours, and sometimes pleomorphic lipoblasts are very scanty in number making it difficult to reach the diagnosis ${ }^{5}$. Prognosis is worse if centrally located, big in size $(>10 \mathrm{~cm})$, and with high mitotic index ${ }^{6}$.

Table 1: Baseline investigations of patient.

\begin{tabular}{|c|c|}
\hline Hb & $\mathbf{1 2 . 2 3 g} / \mathbf{d l ~ ( 1 1 - 1 6 g / d l ) ~}$ \\
\hline WBC count & $11,200 / \mathrm{cmm}$ \\
\hline Platelets & $389,000 / \mathrm{cmm}$ \\
\hline MCV & $\mathbf{7 6 f l}$ \\
\hline Total Bilirubin & $0.57 \mathrm{mg} / \mathrm{dl}$ \\
\hline ALT & $35.8 \mathrm{U} / \mathrm{l}$ \\
\hline ALP & $257 \mathrm{U} / \mathrm{l}$ \\
\hline Creatinine & $0.53 \mathrm{mg} / \mathrm{dl}$ \\
\hline Serum albumin & $2.43 \mathrm{mg} / \mathrm{dl}$ \\
\hline ESR & $80 \mathrm{~mm} / 1 \mathrm{st} \mathrm{hour}$ \\
\hline INR & 1.3 \\
\hline PT & 4 seconds prolonged \\
\hline APTT & 6 seconds prolonged \\
\hline Serum Electrolytes & WNL \\
\hline HBsAg (ELISA) & Non-reactive \\
\hline Anti-HCV (ELISA) & Non-reactive \\
\hline
\end{tabular}

$\mathrm{Hb}$ (Hemoglobin), WBC count (White blood cell count), MCV (Mean Corpuscular Volume), ALT (Alanine Transaminase), ALP (Alkaline Phosphatase), ESR (Erythrocyte Sedimentation Rate), INR (International Normalized Ratio), PT (Prothrombin Time) APTT (Activated Partial Thromboplastin Time), WNL (within normal limits), HBsAg (Hepatitis B surface antigen), anti HCV (anti Hepatitis C Virus) 
Pleomorphic Liposarcoma Presenting As Extra-Cardiac Mediastinal Mass Leading To Cardiac Compression.

Table 1: Differential diagnoses of a mediastinal mass

\begin{tabular}{|c|c|c|c|c|}
\hline & Lesions & Fluid & Fat & Vascular \\
\hline Anterior & $\begin{array}{l}\text { Thymic Lymphoma } \\
\text { Germ Cell Goiter }\end{array}$ & $\begin{array}{c}\text { Thymic Cyst Thymoma Pericardial Cyst } \\
\text { Germ Cell Lymphoma }\end{array}$ & $\begin{array}{l}\text { Germ cell-b Thymolipo- } \\
\text { ma Fat pad }\end{array}$ & $\begin{array}{c}\text { Thyroid Cardiac Coro- } \\
\text { nary arteries }\end{array}$ \\
\hline Middle & $\begin{array}{l}\text { Lymph nodes Du- } \\
\text { plication Cyst Arch } \\
\text { anomaly }\end{array}$ & $\begin{array}{l}\text { Duplication Cyst Necrotic nodes } \\
\text { Pericardial recess Retroperitoneal }\end{array}$ & $\begin{array}{l}\text { Lipoma Esophageal } \\
\text { Fibro Vascular polyp }\end{array}$ & $\begin{array}{l}\text { Arch anomaly Azygous } \\
\text { vein Vascular nodes }\end{array}$ \\
\hline Posterior & $\begin{array}{c}\text { Neurogenic } \\
\text { Bone and marrow }\end{array}$ & $\begin{array}{l}\text { Neuroenteric Cyst Schwannoma Menin- } \\
\text { gocele }\end{array}$ & $\begin{array}{l}\text { Extramedullary Hemato- } \\
\text { poiesis }\end{array}$ & Descending aorta \\
\hline $\begin{array}{l}>1 \mathrm{com}- \\
\text { partment }\end{array}$ & $\begin{array}{c}\text { Infection } \\
\text { Hemorrhage } \\
\text { Lung Cancer }\end{array}$ & Lymphangioma Mediastinitis & Liposarcoma & Hemangioma \\
\hline
\end{tabular}

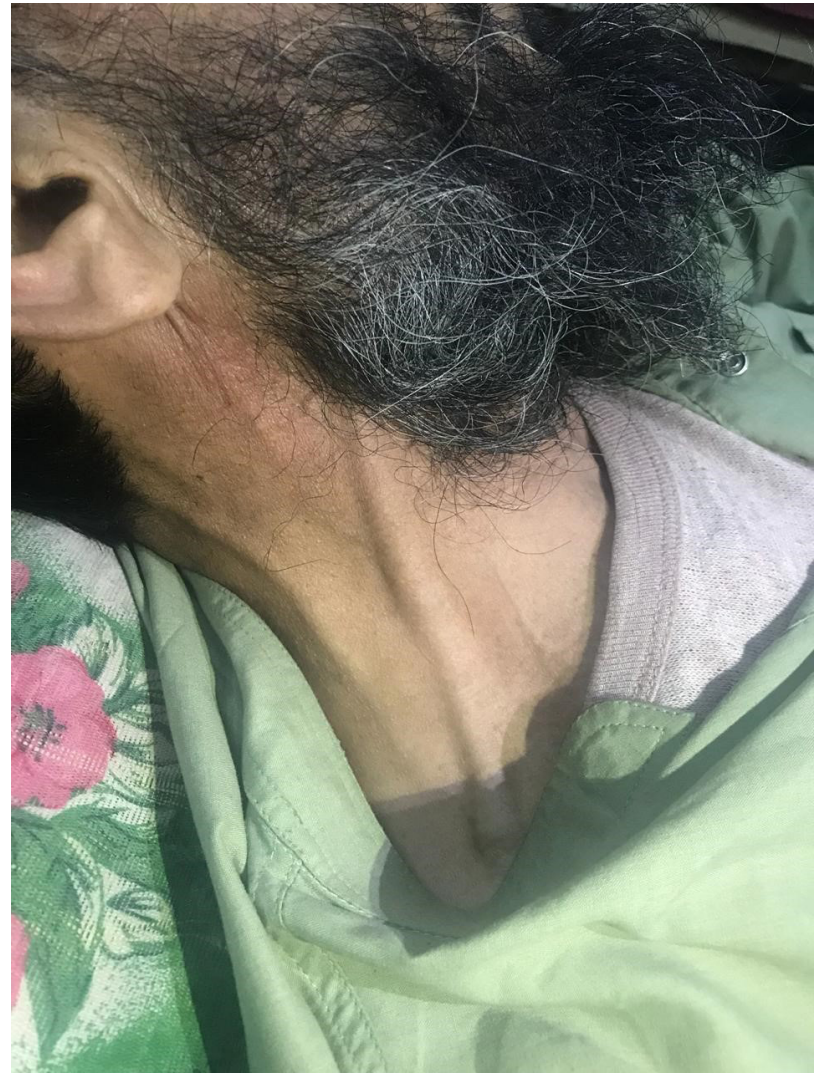

Fig 1: Distended neck veins and raised JVP

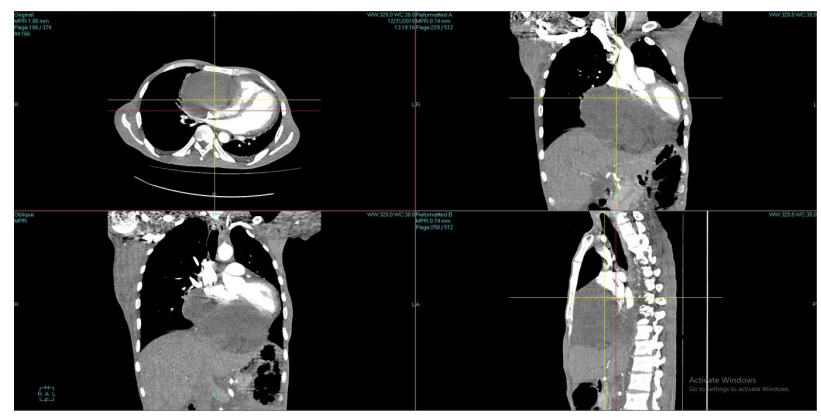

Fig 1: Distended neck veins and raised JVP
Pleomorphic liposarcoma is asymptomatic at the early stage, but compression and visceral invasion develops as the tumor grows. Tumours located in mediastinum present as edema, raised JVP, breathlessness, distended neck veins, ascites and pleural effusion. Pleomorphic liposarcomas recur and metastasize frequently. The fiveyear survival rate is reported as $60 \%^{5}$. Imaging such as CT/MDCT, Magnetic Resonance Imaging (MRI), and ultrasound are important before surgery to stage and grade the tumor ${ }^{4}$. Morphologically, these tumours are defined by the presence of multivacuolated pleomorphic lipoblasts, and immunostaining usually identifies $\mathbf{S} 100$ protein as the major protein in lipoblasts. Molecular features comprise of complicated karyotypes, and commonly TP53 and RB1 gene inactivation. To confirm the diagnosis, biopsy samples are taken from adipose and non-adipose tissues.

Complete surgical excision is the mainstay of treatment. Tumours that are unresectable are debulked to relieve symptoms. Recurrence of deep seeded mass is very common after surgery so radiotherapy is also given in some cases $^{7}$. In certain aggressive cases, adjuvant chemotherapy is employed in addition to surgery. However, there is no consensus on the use of routine radiotherapy and chemotherapy, and proper guidelines are not available to date ${ }^{8}$.

\section{CONCLUSION}

It can thus be concluded that not all patients presenting with symptoms attributable to involvement of cardiovascular system actually have cardiac conditions. Rarely extra cardiac masses can also manifest as dyspnea and chest pain. Advanced investigations and involvement of interventional radiologists for image guided biopsy help in reaching a diagnosis in such cases.

\section{REFERENCES}

1. Fletcher CDM. WHO classification of tumours of soft tissue and bone. Lyon (France): IARC pressQ11 WHO; 2013.

2. Dei Tos AP. Liposarcomas: diagnostic pitfalls and new 
insights. Histopathology 2014;64(1):38-52.

3. Peterson JJ, Kransdorf MJ, Bancroft LW, et al. Malignant fatty tumors: classification, clinical course, imaging appearance and treatment. Skeletal Radiol 2003;32:493503

4. Wang L, Luo R, Xiong Z, Xu J, Fang D. Pleomorphic liposarcoma: an analysis of 6 case reports and literature review. Medicine. 2018 Feb;97(8).

5. Carvalho SD, Pissaloux D, Crombé A, Coindre JM, Le Loarer F. Pleomorphic Sarcomas: the state of the art. Surgical Pathology Clinics. 2019 Mar 1;12(1):63-105.
6. Hornick JL, Bosenberg MW, Mentzel T, et al. Pleomorphic liposarcoma: clinicopathologic analysis of 57 cases. Am J Surg Pathol 2004;28(10): 1257-67.

7. Choi C, Park JH, Lee CG, et al. Successful salvage treatment of myxoid liposarcoma with multiple peritoneal seeding using helical tomo therapy based intraperitoneal radiotherapy: a case report. BMC Res Notes 2015;8:179.

8. Singer S, Antonescu CR, Riedel E, et al. Histologic subtype and margin of resection predict pattern of recurrence and survival for retroperitoneal liposarcoma. Ann Surg 2003;238:358-70 